\title{
Protocol Approval by Sponsor
}

National Cancer Institute

\section{Source}

National Cancer Institute. Protocol Approval by Sponsor. NCI Thesaurus. Code C142648.

An indication that the sponsor, including all reviewers, have approved the protocol. 